\title{
Geographic differences in clinical characteristics and management of COPD: the EPOCA study
}

\author{
Marc Miravitlles' \\ Cristina Murio² \\ Gema Tirado-Conde' \\ Gur Levy \\ Hana Muellerova ${ }^{4}$ \\ Joan B Soriano ${ }^{5}$ \\ Alejandra Ramirez-Venegas ${ }^{6}$ \\ Fanny WS Ko ${ }^{7}$ \\ Byron Canelos-Estrella ${ }^{8}$ \\ Eduardo Giugno? \\ Miguel Bergna9 \\ Ivan Chérrez ${ }^{10}$ \\ Antonio Anzueto"'
}

'Servei de Pneumologia, Institut Clínic del Tòrax, Hospital Clínic, Barcelona, Spain; ${ }^{2}$ Secció de Pneumologia, Hospital General de Catalunya, Barcelona, Spain; ${ }^{3}$ Servicio de Neumonología, Hospital Universitario de

Caracas, Universidad Central de Venezuela, Caracas, Venezuela; ${ }^{4} \mathrm{GlaxoS}$ mithKline, Greenford, UK and Research Triangle Park, USA; 'Programa de Epidemiología e Investigación Clínica, Fundación CaubetCIMERA Bunyola, Illes Balears, Spain; ${ }^{6}$ Departamento de Investigacion en Tabaquismo y EPOC, Instituto Nacional de Enfermedades Respiratorias, Ciudad de México, México; ${ }^{7}$ Department of Medicine and Therapeutics, The Chinese University of Hong Kong, Hong Kong, New Territories, Peoples Republic of China; ${ }^{8} \mathrm{H}$ ospital Metropolitano, Universidad Central del Ecuador y Pontificia Universidad Católica del Ecuador, Quito, Ecuador; ${ }^{9}$ Hospital del Tórax Dr. Antonio Cetrangolo, Vicente López, Buenos Aires, Argentina; ${ }^{10}$ RESPIRALAB-Hospital Kennedy, Guayaquil, Ecuador; "Division of Pulmonary and Critical Care Medicine at the South Texas Veterans Health Care System Audie L Murphy Division and the University of Texas Health Science Center, San Antonio, TX USA

Correspondence: Marc Miravitlles Pneumology Department, Institut Clínic del Tòrax, Hospital Cliníc, Villarroel I70, Barcelona 08036, Spain

$\mathrm{Tel} / \mathrm{Fax}+34932275549$

Emailmarcm@clinic.ub.es

\begin{abstract}
Aims: Data on differences in clinical characteristics and management of COPD in different countries and settings are limited. We aimed to characterize the profile of patients with COPD in a number of countries and their treatment in order to evaluate adherence to recommendations of international guidelines.
\end{abstract}

Method: This was an observational, international, cross-sectional study on patients with physician-diagnosed COPD. Demographic and clinical characteristics, risk factors, and treatment were collected by their physician via an internet web-based questionnaire developed for the study.

Results: A total of 77 investigators from 17 countries provided data on 833 patients. The countries with the highest number of patients included were: Argentina (128), Ecuador (134), Spain (162), and Hong Kong (153). Overall, 79.3\% were men and 81\% former smokers, with a mean $\mathrm{FEV}_{1}=42.7 \%$, ranging from $34.3 \%$ in Hong Kong to $58.8 \%$ in Ecuador. Patients reported a mean of 1.6 exacerbations the previous year, with this frequency being significantly and negatively correlated with $\mathrm{FEV}_{1}(\%)(\mathrm{r}=-0.256 ; \mathrm{p}<0.0001)$. Treatment with short-acting bronchodilators and theophyllines was more frequent in Ecuador and Hong Kong compared with Spain and Argentina, and in patients belonging to lower socioeconomic levels ( $p<0.0001$ for all comparisons). Inadequacy of treatment with inhaled corticosteroids and theophyllines was high, with significant differences among countries.

Conclusions: Differences in the clinical characteristics and management of COPD were significant across countries. Adherence to international guidelines appears to be low. Efforts should be made to disseminate and adapt guidelines to the socioeconomic reality of different settings. Keywords: COPD, epidemiology, EPOCA, socioeconomics

\section{Introduction}

Chronic obstructive pulmonary disease (COPD) is an important public healthcare problem throughout the world. Despite anti-smoking campaigns, its prevalence and mortality rate continue rising every year (Jemal et al 2005). By 2020 it is estimated that COPD will be the fifth cause of disability and the third cause of death (Pauwels et al 2001).

A previous epidemiologic study demonstrated the prevalence of COPD in the general Spanish population between 40 and 70 years of age to be of $9.1 \%$ (Sobradillo et al 2000). However, more importantly, it was observed that $78 \%$ of the patients identified with COPD had not been previously diagnosed with the disease, and $60 \%$ of these patients were not being treated according to the current guidelines (Sobradillo et al 2000; Miravitlles et al 2005). Worldwide, the prevalence of COPD in the general population is estimated to be $1 \%$ across all ages, rising steeply to $8 \%$ to $10 \%$ or higher among those aged 40 years and with nearly $80 \%$ of COPD cases remaining undiagnosed (Chapman et al 2006; Halbert et al 2006). Most of the information on the characteristics of patients with COPD and the patterns of treatment derive from a series of studies 
conducted in North America and Europe (Jackevicius et al 1997; Miravitlles et al 1999; Roche et al 2001; De Miguel et al 2003; Esteban et al 2006). Few studies have provided data from countries from other parts of the world, although the prevalence of COPD is also high in Latin America (Menezes et al 2005), Korea (Kim et al 2005), Taiwan (Wang et al 2007), China (Zhong et al 2007), and Japan (Fukuchi et al 2004). Exposure to respiratory risk factors also differ between geographic areas (Menezes et al 2005; Zhong et al 2007) and these, together with genetic determinants and patterns of smoking, may be the reason for the different characteristics and severity of COPD across countries (Buist et al 2007).

In recent years, epidemiological studies have demonstrated a high and increasing burden of COPD worldwide (Chapman et al 2006; Halbert et al 2006). Moreover, the adherence of treatment to currently accepted guidelines is poor in many countries (Miravitlles et al 1999; Roche et al 2001; Rennard et al 2002; De Miguel et al 2003).

The EPOCA (Enfermedad Pulmonar Obstructiva Crónica en Acción) project is an international web-based survey of doctors and their COPD patients, aimed at comparing the clinical and demographic characteristics, risk factors, and treatment of patients with COPD in different areas of the world using a common protocol through the internet.

\section{Method}

\section{Design}

This was a prospective, international, cross-sectional, observational survey of outpatients diagnosed with COPD. The full data collection period included one year, from December 2005 to December 2006. Data were collected through a webenabled database developed in two languages, English and Spanish. Physicians interested in COPD were recruited using email addresses retrieved from their publications in the field and were invited to participate by email. We aimed to have a representation of different geographic areas by contacting leading investigators who could invite colleagues in their area to join the study. Each investigator was provided with a username and a password to access an online study questionnaire. They were allowed to visualize and modify data of only their own patients. None of the investigators received any payment for participating in the study. Since the main study objectives were descriptive and group comparisons analyses were not planned, we did not make a pre-specified calculation of sample size.

\section{Ethics}

The design of the EPOCA website fulfilled all standards of data protection. Since the server was located in Barcelona
(Spain), the database was declared to the Spanish authorities. No data were collected that could help to identify any single patient in the database. The study was approved by a central ethics committee of the Hospital Clínic of Barcelona, Spain. Informed consent forms were available in the website for downloading in English and Spanish. Written or oral informed consent was obtained for the patients to be included in the study, according to local legislation for observational, non-interventional studies in each country.

\section{Study population}

This was an international, multicenter study in real life practice with a large number of investigators in different settings; therefore we wanted to minimize the risk of misclassification or misdiagnosis as much as possible by not including life-long never smokers. The inclusion criteria were: a) aged older than 40 years; b) smokers or former smokers of at least 10 pack-years; and c) had forced spirometry with a post-bronchodilator $\mathrm{FEV}_{1} / \mathrm{FVC}<70 \%$.

Exclusion criteria were diagnoses of: a) bronchial asthma; b) severe bronchiectasis; c) active tuberculosis and any other chronic infectious disease.

\section{Study variables}

The data collected included age, sex, race, socioeconomic and educational level, and risk factors and clinical characteristics of COPD. Socioeconomic level was categorized by the investigators into high, intermediate, or low according to the gross national income and related to the values for their country. Clinical characteristics of COPD included spirometric results as well as the number of previous exacerbations, emergency visits and hospitalizations due to exacerbations in the previous 12 months and healthcare utilization. Owing to the characteristics of the study, standardization of the spirometric measurements was not possible and each investigator was requested to observe American Thoracic Society criteria for standardization of spirometric procedures (American Thoracic Society 1995). Post-bronchodilator values were used for the analysis whenever available.

The treatment patterns identified included drug treatments, vaccination, rehabilitation, and long-term oxygen therapy. Adherence of prescribed treatments to the current guidelines was assessed for inhaled corticosteroids (ICS) and theophyllines. According to the GOLD guidelines existent at the time of data collection (Pauwels et al 2001), ICS were indicated in patients with $\mathrm{FEV}_{1}$ less than $50 \%$ predicted and with one or more exacerbations and/or visits to emergency rooms and/or admissions. Theophyllines were indicated 
as a second-line treatment after long-acting beta2-agonists (LABAs) and tiotropium in severe patients. To be restrictive in the indication for severe patients, we decided to use a cut off level of $\mathrm{FEV}_{1}$ less than $30 \%$ predicted in patients already treated with LABAs and/or tiotropium. For both groups of drugs the percentages of not indicated drugs among the prescribed and the percentage of not prescribed over the indicated was calculated.

\section{Statistical analysis}

Main variables are presented as percentages. Countries with the largest participation were identified and clinical and treatment characteristics of COPD among the patients recruited in these countries were compared. We used a parametric test (Student's t-test) for variables with a normal distribution and non-parametric test (Mann-Whitney test) for non normally distributed variables. Percentages were compared by means of the chi-squared test. A p value less than 0.05 was considered significant.

Factors potentially associated with exacerbations, prescription of ICS, combination therapy of LABA + ICS, and tiotropium were studied using stepwise logistic regression analysis with the statistical package SAS version 8.02 .

\section{Results}

\section{Patient demographic characteristics}

A total of 77 investigators from 17 countries included data from at least one patient in the database. The total number of patients included was 833, representing a mean of 10.8 patients per investigator. The countries/areas with the highest number of recruited patients were: Spain $(n=162)$, HongKong $(n=153)$, Ecuador $(n=134)$, and Argentina $(n=128)$; these were further analyzed.

Patient demographic characteristics are summarized in Table 1. Mean age was $69.5(\mathrm{SD}=10.2)$ years, $78.2 \%$ of participants were men, and only $19.4 \%$ were active smokers. Mean tobacco consumption for both smokers and ex-smokers was 47.7 pack-years ( $\mathrm{SD}=34$ pack-years). Most of the patients had attended, either finished $(24.5 \%)$ or unfinished (29.3\%), only primary school, and only $8.3 \%$ had a university degree. Most individuals were retired (59.4\%) and only $23.2 \%$ were active, either part- or full-time, workers. According to the investigator's perception, $38.2 \%$ of patients belonged to a lower socioeconomic class, $54.4 \%$ to a middle class, and $7.2 \%$ were ranked as upper class.

There were significant differences in most of the demographic characteristics across countries. For instance, patients in Hong Kong showed the lowest body mass index

Table I Demographic and socioeconomic characteristics of the study population

\begin{tabular}{|c|c|c|c|c|c|c|}
\hline Variable & Global $\mathbf{N}=833$ & Argentina $N=128$ & Ecuador $N=134$ & Spain $N=162$ & Hong Kong $N=153$ & p value \\
\hline Sex, men, \% & 79.3 & 71.1 & 70.9 & 90.7 & 90.8 & $<0.0001$ \\
\hline Age, years & $69.5(10.2)$ & $66.8(8.9)$ & 71.7 (I2.0) & $69.0(10.2)$ & $74.9(7.1)$ & $<0.000$ I \\
\hline $\mathrm{BMI}, \mathrm{kg} / \mathrm{m}^{2}$ & $25.0(5)$ & $25.5(4.3)$ & $25.6(5.2)$ & $26.4(4.8)$ & $21.7(3.9)$ & $<0.000$ I \\
\hline Active smokers, \% & 19 & 14 & 18.1 & 20.1 & 20 & 0.53 \\
\hline Pack-years & $46.9(33.1)$ & $58.1(31.1)$ & $33.4(31.7)$ & $46.9(29.9)$ & $45.2(33.8)$ & $<0.000$ I \\
\hline Biomass exposure, $\%$ & 22.9 & 15.7 & 32.3 & 8.1 & 43 & $<0.000$ I \\
\hline Comorbidity, \% & 42.5 & 38.1 & 41.4 & 63.4 & 42.1 & $<0.000$ I \\
\hline \multicolumn{7}{|l|}{ Socioeconomic, \% } \\
\hline High & 7.2 & 7.9 & 12.5 & 6.3 & 1.3 & $<0.000$ I \\
\hline Intermediate & 53.2 & 62.2 & 50.8 & 67.1 & 21.0 & \\
\hline Low & 39.6 & 29.9 & 36.7 & 26.6 & 77.7 & \\
\hline \multicolumn{7}{|l|}{ Residence, \% } \\
\hline Rural & 11.5 & 7.1 & 12.7 & 18.1 & 6.0 & $<0.000$ I \\
\hline Intermediate & 6.9 & 1.6 & 11.2 & 16.9 & 0 & \\
\hline Urban & 81.6 & 91.3 & 76.1 & 65.0 & 94.0 & \\
\hline \multicolumn{7}{|l|}{ Education, \% } \\
\hline Up to primary & 53.5 & 39.1 & 46.3 & 65.0 & 86.7 & $<0.000$ I \\
\hline Up to secondary & 27.7 & 45.3 & 32.8 & 26.1 & 10.6 & \\
\hline Up to postgraduate & 18.7 & 15.6 & 20.9 & 8.9 & 2.6 & \\
\hline
\end{tabular}

Abbreviations: BMI, body mass index. 
(21.7), the oldest mean age (74.9 years), and the highest proportion of males $(90.8 \%)$. Mean tobacco consumption was highest in Argentina (58.1 pack-years) and highest exposure to biomass smoke was in Hong Kong and Ecuador (43\% and $32.3 \%$, respectively) ( $\mathrm{p}<0.0001$ for all comparisons) (Table 1).

\section{Characteristics of COPD}

Dyspnea on exertion was the most frequent symptom $(97.8 \%)$, with $54.8 \%$ of patients presenting dyspnea MRC degree III or IV. Mean $\mathrm{FEV}_{1} \%$ predicted was $42.7 \%(\mathrm{SD}=17.8 \%)$. The patients presented a mean of $1.6(\mathrm{SD}=2)$ exacerbations, $1.5(\mathrm{SD}=2.5)$ visits to the general practitioner and $2.4(\mathrm{SD}=2.6)$ visits to the chest specialist in the previous 12 months (Table 2). The frequency of exacerbations was significantly, albeit weakly, correlated with COPD severity, as measured by $\operatorname{FEV}_{1}(\%)$, giving a correlation factor $(r)$ of $-0.256(p<0.0001)$ (Figure 1$)$.

Analysis of differences among countries showed several highly significant items. Chronic respiratory symptoms, cough and sputum, were most frequent in Ecuador $(87.4 \%$ and $92.1 \%$, respectively). Mean $\mathrm{FEV}_{1}$ ranged from $34.3 \%$ in Hong Kong to $58.8 \%$ in Ecuador. Use of healthcare resources also differed by country. The mean number of admissions ranged from 1 per patient per year in Hong Kong to 0.4 in Ecuador and the mean number of visits to a chest specialist from 1.8 in Spain and Hong Kong to 4.6 in Argentina ( $\mathrm{p}<0.0001$ for all comparisons) (Table 2 ).

\section{Treatment of COPD}

The most frequently prescribed treatment for COPD was short-acting beta-agonists (SABA) (74.8\%) followed by ipratropium (48.3\%), with large differences between countries. SABAs were prescribed in a range from $90.1 \%$ in Hong Kong to $21.1 \%$ in Spain. Tiotropium was used by $73.9 \%$ of patients in Spain and only $1.9 \%$ in Hong Kong. Combined treatment of LABA and ICS was used by $45.9 \%$ of patients, ranging from $12.5 \%$ in Hong Kong to $72.8 \%$ in Argentina (all differences were statistically significant, Table 3). Oral treatment was prescribed less frequently; theophyllines were used by $25.3 \%$ of the sample, with maximum frequency in Hong Kong (46.6\%). Only $15.6 \%$ of patients were following a rehabilitation program, mostly in Argentina (30.5\%). Interestingly, $58.6 \%$ had received the anti-influenza vaccine the previous year, with the lowest percentage in Ecuador $(22.6 \%)$. Antipneumococcal vaccine was administered to $32.5 \%$, with almost no use in Hong Kong (0.7\%) and a maximum in Argentina (64.4\%).

When compared with recommendations based on international guidelines (Pauwels et al 2001), we observed noncompliance with these recommendations in a significant number of patients. Specifically, 306 patients fulfilled indications for chronic treatment with ICS and 527 were regularly treated with ICS. Up to $27.8 \%$ of those with an indication for ICS treatment were not receiving them, and, according to the guidelines, $41.9 \%$ of patients treated with ICS did not fulfil the indications for treatment. This inadequacy varied

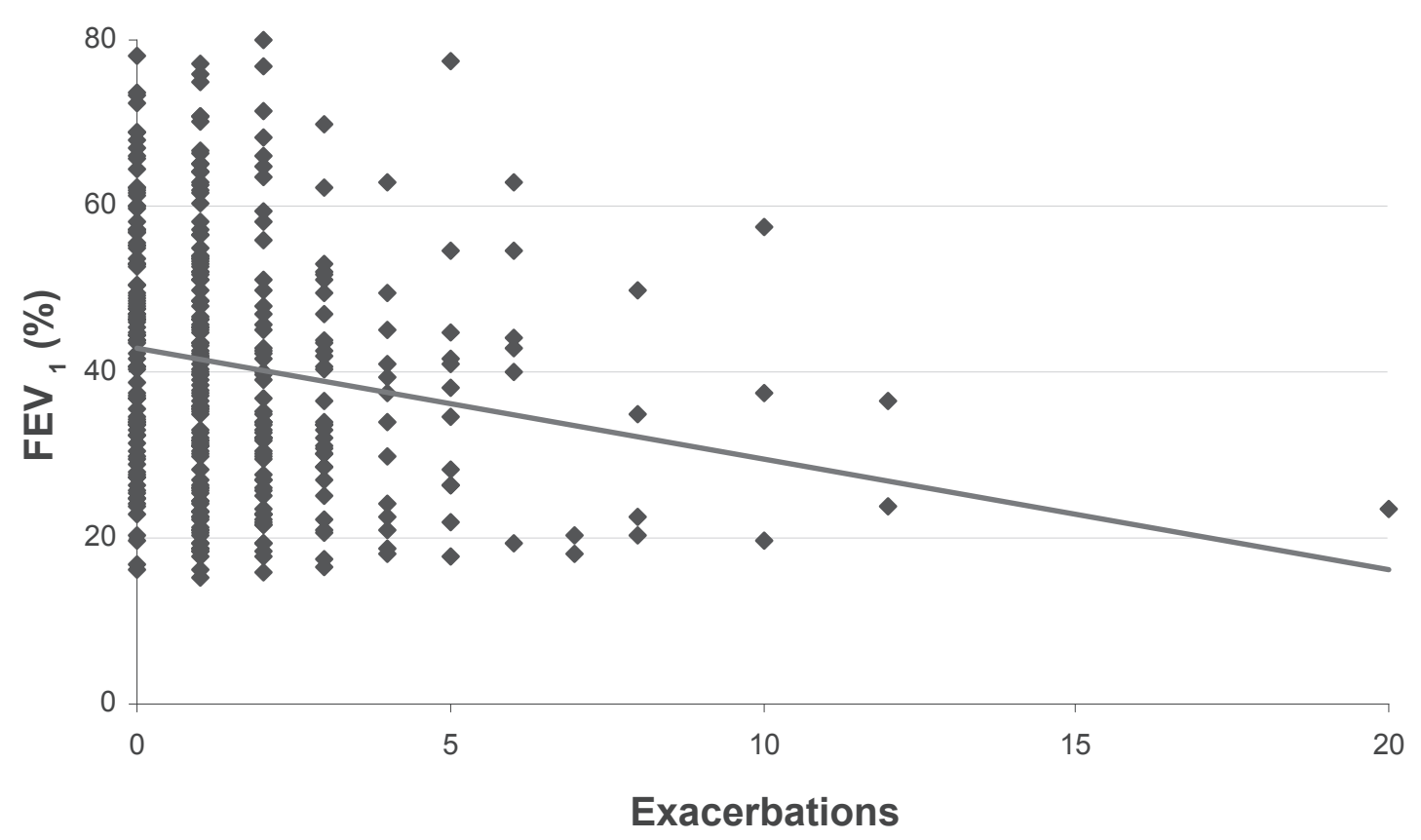

Figure I Correlation between lung function $\left(\mathrm{FEV}_{1}(\%)\right)$ and the frequency of exacerbations the previous year $(r=-0.256 ; \mathrm{p}<0.000 \mathrm{I})$. 
Table 2 Characteristics of COPD

\begin{tabular}{|c|c|c|c|c|c|c|}
\hline Variable & Global $\mathbf{N}=833$ & Argentina $N=128$ & Ecuador $N=134$ & Spain N = I62 & Hong Kong $N=153$ & $\mathrm{p}$ value \\
\hline Years of evolution & 10.1 & II.I & 8.1 & 14.3 & 8.8 & $<0.0001$ \\
\hline \multicolumn{7}{|l|}{ Symptoms, \% } \\
\hline Dyspnea Degree 0 & 2.2 & 0 & 5.9 & 1.5 & 0 & $<0.0001$ \\
\hline Degree I & 11.5 & 2.6 & 16.8 & 10.3 & 3.7 & \\
\hline Degree 2 & 31.4 & 36.2 & 32.8 & 30.1 & 28.3 & \\
\hline Degree 3 & 34.3 & 36.2 & 26.9 & 32.3 & 47.8 & \\
\hline Degree 4 & 20.5 & 25.0 & 17.6 & 25.0 & 20.1 & \\
\hline Chronic cough, \% & 69.6 & 71.2 & 87.4 & 76.6 & 52.3 & $<0.0001$ \\
\hline Sputum, \% & 70.5 & 75.4 & 92.1 & 59.4 & 63.8 & $<0.0001$ \\
\hline \multicolumn{7}{|l|}{ Lung function } \\
\hline $\mathrm{FVC}, \mathrm{ml}$ & $23 \mid 2.2(920.5)$ & 2472.5 (804.9) & $2295.1(750.2)$ & $2709.9(1016.9)$ & I 448.9 (602.5) & $<0.0001$ \\
\hline FVC,\% predicted & $59.7(19.4)$ & $62.2(16.0)$ & $65.4(17.7)$ & $66.8(19.5)$ & $40.3(14.8)$ & $<0.0001$ \\
\hline $\mathrm{FEV}_{1}, \mathrm{~mL}$ & I| $43.8(5 \mid 8.7)$ & I I $47.2(465.4)$ & $1406.0(627.1)$ & I $279.5(547.0)$ & $841,6(391.4)$ & $<0.0001$ \\
\hline $\mathrm{FEV}_{1}, \%$ predicted & $42.7(17.8)$ & $4 I . I(15.4)$ & $58.8(23.5)$ & $44.3(17.3)$ & 34.3 (13.9) & $<0.0001$ \\
\hline $\mathrm{FEV}_{1} / \mathrm{FVC}$ & $50.6(14.5)$ & $47.0(13.7)$ & $60.9(15.9)$ & $48.0(13.1)$ & $59.0(14.2)$ & $<0.0001$ \\
\hline \multicolumn{7}{|l|}{ During the last year } \\
\hline Number of exacerbations & $1.6(2.0)$ & $2.0(1.9)$ & $0.9(1.4)$ & $1.8(1.9)$ & $1.9(3.0)$ & $<0.0001$ \\
\hline Emergency visits & $0.9(1.5)$ & I.3 (I.8) & $0.3(0.7)$ & $0.9(1.5)$ & $1.3(2.1)$ & $<0.0001$ \\
\hline Admissions & $0.6(1.0)$ & $0.5(1.1)$ & $0.4(0.8)$ & $0.6(1.0)$ & $1.0(1.3)$ & $<0.0001$ \\
\hline IC admissions & $0.1(0.3)$ & $0.2(0.5)$ & $0.0(0.3)$ & $0.1(0.4)$ & $0.0(0.3)$ & $<0.0001$ \\
\hline Visits to GP & $1.5(2.5)$ & $2.6(3.7)$ & I.6 (3.2) & $2.0(3.2)$ & I.2(2.5) & $<0.0001$ \\
\hline Visits to chest specialist & $2.4(2.6)$ & $4.6(3.8)$ & $2.8(2.7)$ & $1.8(1.8)$ & I.8 (2.0) & $<0.0001$ \\
\hline
\end{tabular}

Abbreviations: FVC, forced vital capacity; FEV , forced expiratory volume in the first second; IC, intensive care; GP, general practitioner.

significantly among countries (Table 4). Theophyllines were administered to 222 patients while 123 had indications for treatment with this drug. However, up to $79.6 \%$ of the patients with indication for theophyllines were not receiving them, and, according to the guidelines, $26.6 \%$ of patients treated with theophyllines had no indication. Differences were, again, large and significant among countries (Table 4).

\section{Differences according to estimated social class}

Patients of a lower socioeconomic class were older and had a more severe impairment of $\mathrm{FEV}_{1}(\%)$ than patients belonging to an upper class. They were also more exposed to biomass smoke (36.1\% vs $13.5 \%$ and $18.6 \%$ for low, middle, and high class, respectively, $\mathrm{p}<0.0001$ ). Lower class patients tended to require more visits to emergency rooms and admissions for exacerbations ( $\mathrm{p}=0.058$ and $\mathrm{p}=0.083$, respectively) (Table 5 ).

Treatments differed according to the class; SABAs, LABAs, ipratropium, and theophyllines were more frequently prescribed to lower class patients and tiotropium and combination therapy LABA + ICS were less frequently used by lower class patients (all comparisons $\mathrm{p}<0.0001$ ).
Rehabilitation was more frequent in upper class patients (31.5\% compared with $15.7 \%$ and $13.4 \%$ in middle and lower classes, respectively; $p=0.0036$ ) $($ Table 5 ).

\section{Analysis of factors associated with exacerbations and prescribed drugs}

Stepwise regression analysis identified the variables significantly associated with the frequency of exacerbations categorized as $0-1$ versus more than 1 . Older age, increasing baseline dyspnea, and use of ICS were associated with an increased frequency of exacerbations in the model (Table 6a).

In terms of pharmacologic treatment, use of ICS was significantly associated with more impaired lung function and the presence of expectoration. Patients belonging to the upper class, active smokers, and Spanish were less likely to use ICS alone compared with lower classes, former smokers, and patients from Argentina, Ecuador, and Hong Kong (Table 6b). In contrast, Spanish patients were more likely to use combination therapy with LABA + ICS than patients from Ecuador or Hong Kong, and patients with secondary schooling, former smokers, or with chronic cough were more likely to be prescribed the combination of LABA + ICS 
Table 3 Treatment administered for stable COPD

\begin{tabular}{|c|c|c|c|c|c|c|}
\hline Variable & Global $\mathbf{N}=833$ & Argentina $N=128$ & Ecuador $N=134$ & Spain $N=162$ & Hong Kong $N=153$ & p value \\
\hline \multicolumn{7}{|l|}{ Inhaled treatment, \% } \\
\hline SABA & 74.8 & 85.6 & 69.5 & 75.3 & 97.4 & $<0.000$ I \\
\hline Ipratropium & 48.3 & 52.5 & 30.4 & 21.1 & 90.1 & $<0.0001$ \\
\hline Tiotropium & 35.5 & 33.9 & 40.6 & 73.9 & 1.9 & $<0.000$ I \\
\hline LABA & 9 & 2.5 & 13.3 & 9.1 & 2.6 & 0.0007 \\
\hline ICS & 21.8 & 12.7 & 31.2 & 5.6 & 44.7 & $<0.000$ I \\
\hline LABA/ICS & 45.9 & 72.8 & 35.9 & 68.3 & 12.5 & $<0.0001$ \\
\hline \multicolumn{7}{|l|}{ Oral treatment, \% } \\
\hline Teophyllines & 25.3 & 18.6 & 26.6 & 7.1 & 46.6 & $<0.0001$ \\
\hline Mucolytics & 10.1 & 5.9 & 13.2 & 20.4 & 1.3 & $<0.0001$ \\
\hline Oral corticosteroids & 4.4 & 3.4 & 11.7 & 3.5 & 0 & $<0.000$ I \\
\hline \multicolumn{7}{|l|}{ Other, \% } \\
\hline LTOT & 21.1 & 14.4 & 17.9 & 24.6 & 17.7 & 0.18 \\
\hline Rehabilitation & 15.6 & 30.5 & 3.1 & 4.9 & 7.9 & $<0.0001$ \\
\hline Antiinfluenza vaccine & 58.6 & 72.0 & 22.6 & 80.3 & 48.7 & $<0.0001$ \\
\hline Antipneumococcal vaccine & 32.5 & 64.4 & 18.7 & 43.6 & 0.7 & $<0.0001$ \\
\hline
\end{tabular}

Abbreviations: SABA, short-acting beta2 agonist; LABA, long-acting beta2-agonist; ICS, inhaled corticosteroid; LTOT, long-term oxygen therapy.

(Table 6c). Finally, use of tiotropium was associated only with geographic variables, with patients from Argentina, Ecuador, or Hong Kong being less likely to be treated with this drug than patients from Spain (Table 6).

\section{Discussion}

This study shows that there are significant and relevant differences in the clinical characteristics, exposure to risk factors, and patterns of management of patients with COPD in different areas of the world. Differences in genetic background may account for part of the variations shown by the results. However, different toxic exposures, differences in socioeconomic and living conditions, and differences in education levels also exist and may be responsible, at least in part, for the variations observed in the manifestations of COPD. Epidemiological studies have demonstrated important variations in the prevalence of smoking in young adults across countries and, as a consequence, a large variation in the prevalence of chronic bronchitis (Cerveri et al 2001) and COPD (De Marco et al 2004). However, the same authors indicated that only $30 \%$ of the geographical variability in prevalence could be explained by differences in smoking habits, suggesting other factors such as environmental exposure or genetic background as contributors to this variability (Cerveri et al 2001).

The clinical characteristics of patients with COPD have been carefully studied in clinical trials (Calverley et al 2007). However, due to the restrictive inclusion and

Table 4 Inadequate treatment for stable COPD

\begin{tabular}{|c|c|c|c|c|c|c|}
\hline Variable & Global N = 833 & Argentina $N=128$ & Ecuador $N=134$ & Spain $N=162$ & Hong Kong $N=153$ & $P$ value \\
\hline \multicolumn{7}{|l|}{ Inhaled corticosteroids } \\
\hline \multicolumn{7}{|l|}{ Indicated $(\mathrm{n}=306)$} \\
\hline \multicolumn{7}{|l|}{ Prescribed $(n=527)$} \\
\hline Indicated, not prescribed & 27.8 & 11.3 & 18.7 & 17.4 & 49 & $<0.0001$ \\
\hline Prescribed, not indicated & 41.9 & 38.6 & 65.1 & 33.3 & 33.3 & $<0.000$ I \\
\hline \multicolumn{7}{|l|}{ Theophyllines } \\
\hline \multicolumn{7}{|l|}{ Indicated $(n=123)$} \\
\hline \multicolumn{7}{|l|}{ Prescribed $(n=222)$} \\
\hline Indicated, not prescribed & 79.6 & 85 & 72.2 & 92.9 & 0 & 0.008 \\
\hline Prescribed, not indicated & 26.6 & 4.5 & 26.4 & 0 & 33.8 & 0.0016 \\
\hline
\end{tabular}


Table 5 Demographic and clinical characteristics of patients according to estimated social class

\begin{tabular}{|c|c|c|c|c|}
\hline Variables & Low $\mathbf{N}=324$ & Intermediate $N=436$ & High $\mathbf{N}=59$ & p value \\
\hline Sex, men & 76.5 & 81.9 & 72.8 & 0.091 \\
\hline Age, years & $71.3(9.6)$ & $68.8(10.2)$ & $63.4(10.5)$ & $<0.000$ I \\
\hline Active smoker & 16.9 & 20.2 & 24.1 & 0.34 \\
\hline Pack-years & $45.6(33.2)$ & $46.7(31.6)$ & $53.3(39.6)$ & 0.49 \\
\hline Biomass exposure & 36.1 & 13.5 & 18.6 & $<0.000$ I \\
\hline Years of evolution & $9.3(8.5)$ & $10.7(10.3)$ & $10(9.1)$ & 0.34 \\
\hline Comorbidity & 40.2 & 44.8 & 37 & 0.32 \\
\hline Baseline dyspnea & & & & 0.007 \\
\hline Degree 0 & 2.4 & 2 & 2 & \\
\hline Degree I & 6.3 & 13.7 & 26 & \\
\hline Degree 2 & 30.5 & 32.1 & 26 & \\
\hline Degree 3 & 37.5 & 32.6 & 30 & \\
\hline Degree 4 & 23.1 & 19.4 & 16 & \\
\hline \multicolumn{5}{|l|}{ Lung function } \\
\hline FVC, mL & $2012.5(829.2)$ & $2442.4(885.3)$ & $3033.5(1116.5)$ & $<0.000$ I \\
\hline FVC, \% & $55.5(19.5)$ & $61.5(18.4)$ & $69.2(19.9)$ & $<0.0001$ \\
\hline $\mathrm{FEV}_{1}, \mathrm{~mL}$ & $1053.2(485.8)$ & II 64.4 (5I5.5) & | 487.8 (587. I) & $<0.0001$ \\
\hline $\mathrm{FEV}_{1}, \%$ & $42.1(18.4)$ & $42.1(17.0)$ & $47.4(18.1)$ & $0.1311 *$ \\
\hline $\mathrm{FEV}_{1} / \mathrm{FVC}, \%$ & $53.8(15.2)$ & $48.2(13.7)$ & $50.5(13.3)$ & 0.0002 \\
\hline \multicolumn{5}{|l|}{ Previous 12 months } \\
\hline Medical visits GP & $1.5(2.4)$ & $1.6(2.8)$ & I.I (I.5) & 0.47 \\
\hline Medical visits specialist & $2.4(2.2)$ & $2.5(2.9)$ & $2.2(2.6)$ & 0.43 \\
\hline Exacerbations & I.7 (2.4) & $1.5(1.7)$ & I.4 (I.5) & 0.74 \\
\hline Emergency visits & I.I (I.8) & $0.8(1.3)$ & $0.6(1.3)$ & 0.058 \\
\hline Admissions & $0.7(1.2)$ & $0.5(0.8)$ & $0.5(0.8)$ & 0.083 \\
\hline \multicolumn{5}{|l|}{ Treatment } \\
\hline SABA & 83.6 & 7I.I & 53.7 & $<0.000$ I \\
\hline Ipratropium & 64 & 39.4 & 24.1 & $<0.0001$ \\
\hline Tiotropium & 22.5 & 42.4 & 57.4 & $<0.000$ I \\
\hline LABA & 7.5 & 7.6 & 29.6 & $<0.000$ I \\
\hline ICS & 34.3 & 13.7 & 9.2 & $<0.0001$ \\
\hline LABA/ICS & 34.3 & 54.6 & 44.4 & $<0.000$ I \\
\hline Theophyllines & 35.6 & 23.7 & 22.2 & 0.0014 \\
\hline Mucolytics & 6.5 & 14.4 & 9.2 & 0.0033 \\
\hline Rehabilitation & 13.4 & 15.7 & 31.5 & 0.0036 \\
\hline LTOT & 21.9 & 20.6 & 22.2 & 0.8988 \\
\hline Antiinfluenza vaccination & 56.2 & 62.2 & 48.1 & 0.067 \\
\hline Antipneumococcal vaccination & 23.8 & 38.9 & 35.1 & $<0.000$ I \\
\hline
\end{tabular}

$*_{p}=0.0447$ between high and low social class.

Abbreviations: FVC, forced vital capacity; FEV , forced espiratory volume in the first second; GP, general practitioner; SABA, short-acting beta2-agonist; LABA, long-acting beta2-agonist; ICS, inhaled corticosteroid; LTOT, long-term oxygen therapy.

exclusion criteria, these characteristics differ significantly from those of COPD patients in general practice. In fact, a Swedish study demonstrated that less than $20 \%$ of patients with COPD attended by general practitioners share characteristics with patients included in clinical trials (Herland et al 2005). Therefore, surveys conducted in real clinical practice in different areas of the world with broad inclusion criteria are required to identify the characteristics, risk factors, and patterns of management of COPD in real life. 
Table 6 Multivariate stepwise regression models of dependent variables significantly and independently associated with the following independent variables: frequency of exacerbations ( $0-1$ versus $>1$ ), treatment with ICS, combination therapy LABA + ICS and tiotropium (all presented as yes versus no)

\begin{tabular}{llll}
\hline a) Frequency of exacerbations & & & \\
\hline Variable & Point estimate & 95\% confidence limits & p value \\
\hline Age $>75$ vs $65-75$ yrs & 0.948 & $0.596-1.508$ & 0.8223 \\
Age $>75$ vs $<65$ yrs & 2.088 & $1.280-3.406$ & 0.0032 \\
Dyspnea II vs 0-I & 4.399 & $1.618-11.962$ & 0.0037 \\
Dyspnea III vs 0-I & 6.223 & $2.308-16.782$ & 0.0003 \\
Dyspnea IV vs 0-I & 14.249 & $5.110-39.735$ & $<0.000$ I \\
Inhaled corticosteroids & 2.535 & 1.6 II-3.99I & $<0.000$ I \\
\hline
\end{tabular}

b) Treatment with inhaled corticosteroids

\begin{tabular}{llll}
\hline Variable & Point estimate & $95 \%$ confidence limits & P value \\
\hline FEVI $<50 \%$ vs $>50 \%$ & 1.994 & $1.059-3.754$ & 0.0326 \\
Expectoration & 2.595 & $1.457-4.619$ & 0.0012 \\
Low class vs high class & 5.875 & $1.907-18.098$ & 0.0020 \\
Middle class vs high & 4.667 & $1.620-13.448$ & 0.0043 \\
class & & & $<0.0001$ \\
Former vs active & 4.663 & $2.386-9.113$ & 0.2148 \\
smoker & & & 0.5193 \\
Argentina vs Spain & 1.599 & $0.762-3.358$ & $<0.0001$ \\
Ecuador vs Spain & 1.484 & $0.447-4.923$ & $0.088-0.388$ \\
Hong Kong vs Spain & 0.185 & & \\
\hline
\end{tabular}

c) Treatment with combination LABA + ICSs

\begin{tabular}{llll}
\hline Variable & Point estimate & 95\% confidence limits & P value \\
\hline Education secondary vs primary & 1.689 & $1.031-2.766$ & 0.0373 \\
Education postgraduate vs primary & 0.925 & $0.482-1.778$ & 0.8160 \\
Cough & 1.756 & $1.073-2.875$ & 0.0252 \\
Former vs active smoker & 3.139 & $1.754-5.617$ & 0.0001 \\
Argentina vs Spain & 1.110 & $0.628-1.962$ & 0.7203 \\
Ecuador vs Spain & 0.181 & $0.101-0.326$ & $<0.0001$ \\
Hong Kong vs Spain & 0.073 & $0.039-0.137$ & $<0.0001$ \\
\hline
\end{tabular}

d) Treatment with tiotropium

\begin{tabular}{llll}
\hline Variable & Point estimate & 95\% confidence limits & P value \\
\hline Former vs active smoker & 1.442 & $0.803-2.590$ & 0.2198 \\
Argentina vs Spain & 0.166 & $0.096-0.286$ & $<0.0001$ \\
Ecuador vs Spain & 0.234 & $0.135-0.403$ & $<0.0001$ \\
Hong Kong vs Spain & 0.007 & $0.002-0.22$ & $<0.0001$ \\
\hline
\end{tabular}

Data from international surveys of patients with COPD in real life are scarce. Two previous surveys identified patients through random telephone calls (Rennard et al 2002; Miravitlles et al 2007). The Confronting Survey performed in 6 European countries, the US, and Canada demonstrated the significant impact of COPD on daily life activities and how patients underestimate disease severity. Furthermore, only $45 \%$ of patients had undergone spirometry for diagnosis (Rennard et al 2002). Similarly, in a large survey conducted in Spain in 6,758 adults, the prevalence of chronic respiratory 
symptoms was $36 \%$, but only $56 \%$ of the individuals with symptoms consulted a physician and of these, only $42 \%$ underwent spirometry (Miravitlles et al 2006). The Perceive Study, conducted in 5 European countries and the US demonstrated the burden associated with the exacerbations of COPD and the impact of the exacerbations on daily life activities (Miravitlles et al 2007a). In contrast with the current study, no confirmation of the diagnosis or severity of COPD was possible because of the lack of spirometry in the aforementioned surveys. Moreover, they collected information only on patients from Europe and North America and no data from Asia-Pacific or Latin America were available. In our study only patients with confirmed COPD by spirometry were included and most of the patients had post-bronchodilator values. However, a few patients had only one value registered for spirometry. Most were severe patients who needed to take their bronchodilators to relieve their severe dyspnea before attending the clinics and perform spirometry; therefore, their values can be considered post-bronchodilator values. Additionally, although we recognize the importance of COPD in never smokers, we recruited only patients who were either smokers or ex-smokers to avoid misclassification of patients with other respiratory diseases such as asthma.

Recent well-conducted epidemiological studies have provided information on the burden of the disease in those areas. The PLATINO project observed a prevalence of COPD (GOLD II to IV) in Latin America ranging from 2.9\% in Mexico City to $7.1 \%$ in Montevideo, again highlighting the importance of geographical variation (Menezes et al 2005). Using the same protocol, the BOLD initiative, performed in 12 sites around the world, demonstrated a significant variation in the prevalence of COPD (GOLD II to IV), ranging from $8.5 \%$ in males in Reykjavik to $22.2 \%$ in Cape Town and from $3.7 \%$ in women in Hanover to $16.7 \%$ in Cape Town. Interestingly, significant heterogeneity was observed between sites, especially in women (Buist et al 2007). These differences can be observed among different areas of the same country, as was demonstrated in a Spanish study in 7 different cities, in which the prevalence of COPD ranged from $4.9 \%$ to $18 \%$ (Sobradillo et al 2000). Not only prevalence but also severity of impairment in functional status and perceived health may vary in different racial groups within the same country, as demonstrated in different population groups in the US (Adams et al 2006). At least part of these differences can be caused by exposure to other risk factors, such as biomass smoke exposure (Ramirez-Venegas et al 2006) or environmental exposure (Montnémery et al 2001). A significant exposure to biomass fuel was declared by $42 \%$ of the COPD patients in Hong Kong and in 32\% in Ecuador, compared with only $8 \%$ in Spain or $15 \%$ in Argentina. Other possibilities are the different perception of symptoms, which have demonstrated to be related to cultural factors in some racial groups (Han et al 2005).

We observed significant differences in the characteristics and management of the disease according to the socioeconomic status of the patients. It is important to point out the existing limitations for adequate classification of socioeconomic status among different countries. However, the results obtained are consistent with other published national series (Montnémery et al 2001; Ellison-Loschmann et al 2007; Hegwald and Crapo et al 2007). The current results demonstrate a higher exposure to biomass fuel in patients with lower socioeconomic status and better lung function in upper classes. Treatment also showed some differences, with a higher use of old, cheaper, SABAs and theophyllines and a lower use of tiotropium and combination therapy with LABA + ICS in patients of lower class and education. This variation in the use of drugs may largely be due to the economic level of the patients since national health coverage was poor in the countries showing the highest differences. These results concur with other epidemiological surveys which demonstrated a significant negative correlation between lung function and socioeconomic status (Hegewald and Crapo 2007). However, there is a lack of evidence of the long-term impact of inadequate or insufficient treatment of COPD in patients of lower socioeconomic status, as observed in our study.

Exacerbations are a frequent event in the natural history of COPD. Our patient population had had a mean of 1.6 episodes the previous year and the frequency of exacerbations was significantly associated with an older age and a more severe baseline dyspnea. There was a weak but significant correlation between a more impaired $\mathrm{FEV}_{1}(\%)$ and more frequent exacerbations $(r=-0.256 ; \mathrm{p}<0.0001)$. The relationship between impaired lung function and more frequent exacerbations has been observed in clinical trials (Burge and Wedzicha 2003) and observational studies (Miravitlles et al 1999), but it has also been demonstrated in this study in heterogeneous populations from different countries, which together reinforces the relationship between the natural history of the disease and the frequency of exacerbations.

Most patients received treatment for COPD and this treatment differed widely among countries, suggesting that implementation of international guidelines is not uniform around the world. SABAs are widely used, but more new and expensive drugs such as tiotropium and combination 
therapy with LABA + ICS are more frequently prescribed in countries with a higher economic level and in patients of higher socioeconomic classes. In fact, country was the only variable significantly associated with prescription of the three drugs analyzed in multivariate models. The lack of adherence to treatment guidelines for COPD has been extensively demonstrated in previous studies (Jackevicius et al 1997; Miravitlles et al 1999; Roche et al 2001; Rennard et al 2002; De Miguel et al 2003; Esteban et al 2006; Miravitlles et al $2007 b$ ). Our results highlight this problem and identify some of the aspects related to the prescription of different drugs. Another interesting observation is the analysis of prescription of theophyllines and ICS. Evolutionary studies have demonstrated that theophyllines have been replaced by the use of ICS in patients with COPD over time (Van Andel et al 1999). However, the use of theophyllines is still very frequent in countries such as Hong Kong and Ecuador, probably for economic reasons. According to the guidelines at the time of data collection, there was a lack of adjustment in the use of these two drugs. According to the guidelines, $41.9 \%$ of the prescriptions of ICS were not prescribed correctly and, conversely, in $27.8 \%$ of the cases in which they were indicated, the ICS were not prescribed. Similarly, a large survey on 11,973 patients with COPD in Spain showed that $69 \%$ of patients with mild COPD were receiving ICS regularly (Viejo-Bañuelos et al 2006). A recent study has shown that some patients with COPD receiving ICS had clinical characteristics similar to asthma (Miravitlles et al 2007b) which could justify its use even if $\mathrm{FEV}_{1}$ is above $50 \%$ predicted (Siva et al 2007). Most patients with an indication of theophyllines were not receiving them, perhaps because of the risk of side effects, whereas $26.6 \%$ of patients treated with theophyllines should have received other more appropriate drugs.

The EPOCA study was an attempt to characterize COPD patients and patterns of management in different countries by using the same protocol and with a simple and fast data collection through a web-enabled database on the internet. This is one of the few observational studies performed in COPD patients using this new technology (Miravitlles et al 2002). Despite its relatively small sample size, it has allowed the identification of significant differences in the clinical characteristics and management of COPD across countries. The results do not aim to be fully representative of the populations of COPD patients in each of the countries participating. The selection of investigators was not random or weighted according to the population of the countries. To perform such a full-scale representative survey would be a tremendous task, clearly beyond the scope and the possibilities of our study. However, keeping this limitation in mind, our results demonstrate, at an international level, the large variability of characteristics of COPD patients and their management. The results obtained have shown that the characteristics of patients with COPD vary in different countries and patterns of management differ according to socioeconomic factors. A significant number of patients were not receiving treatment according to guidelines, which may result in suboptimal effects of therapy. More efforts are required to disseminate and implement international guidelines and attempt to adapt these guidelines to the socioeconomic reality of each setting. The national scientific societies may play an important role in disseminating the guidelines through national key opinion leaders, local publications translated into their own languages and local scientific meetings.

\section{Acknowledgments}

The EPOCA study was funded by an educational grant from GlaxoSmithKline R\&D.

\section{Author contribution}

Marc Miravitlles, study design, analysis and interpretation of data, and writing of the manuscript. Antonio Anzueto, study design, analysis and interpretation of data, and critical review of the manuscript. Cristina Murio, analysis and interpretation of data, monitoring of the study, and critical review of the manuscript. Gema Tirado-Conde, Gur Levy, Alejandra Ramirez-Venegas, Fanny Ko, Byron CanelosEstrella, Eduardo Giugno, Miguel Bergna, and Ivan Chérrez, data collection, critical review of the manuscript. Hana Muellerova securing funding for the study, study design, and critical review of the manuscript. Joan B. Soriano, study design, analysis and interpretation of data and critical review of the manuscript.

\section{Disclosures}

$\mathrm{HM}$ is an employee of GlaxoSmithKline, the company sponsoring this study. The other authors have no conflicts of interest to declare in relation to this manuscript.

\section{References}

Adams SG, Anzueto A, Pugh JA, et al. 2006. Mexican American elders have similar severities of COPD despite less tobacco exposure thank European American elders. Respir Med, 100:1966-72.

American Thoracic Society. 1995. Standardization of spirometry, 1994 update. Am J Respir Crit Care Med, 152:1107-36.

Buist AS, McBurnie MA, Vollmer WM, et al. 2007. International variation in the prevalence of COPD (The BOLD study): a population-based prevalence study. Lancet, 370:741-50.

Burge S, Wedzicha JA. 2003. COPD exacerbations: definitions and classification. Eur Respir J, 21:46-53. 
Calverley PMA, Anderson JA, Celli B, Ferguson GT, et al. 2007. Salmeterol and fluticasone propionate and survival in chronic obstructive pulmonary disease. $N$ Engl $J$ Med, 356:775-89.

Cerveri I, Accordini S, Verlato G, et al. 2001. Variations in the prevalence across countries of chronic bronchitis and smoking habits in young adults. Eur Respir J, 18:85-92.

Chapman KR, Mannino DM, Soriano JB, et al. 2006. Epidemiology and costs of chronic obstructive pulmonary disease. Eur Respir $J$, 27:188-207.

De Marco R, Accordini S, Cerveri I, et al. 2004. An international survey of chronic obstructive pulmonary disease in young adults according to GOLD stages. Thorax, 59:120-5.

De Miguel J, Izquierdo Alonso JL, Rodríguez González-Moro, et al. 2003. Tratamiento farmacológico de la EPOC en dos niveles asistenciales. Grado de adecuación a las normativas recomendadas. Arch Bronconeumol, 39:195-202.

Ellison-Loschmann L, Sunyer J, Plana E, et al. 2007. Socioeconomic status, asthma and chronic bronchitis in a large community-based study. Eur Respir J, 29:897-905.

Esteban C, Moraza J, Quintana JM, et al. 2006. Use of medication and quality of life among patients with COPD. Respir Med, 100:487-95.

Fukuchi Y, Nishimura M, Ichinose M, et al. 2004. COPD in Japan: the Nippon COPD epidemiology study. Respirology, 9:458-65.

Halbert RJ, Natoli JL, Gano A, et al. 2006. Global burden of COPD: systematic review and meta-analysis. Eur Respir J, 28:523-32.

Han J, Zhu Y, Li S, Chen X, et al. 2005. Respiratory complaints in Chinese. Cultural and diagnostic specificities. Chest, 127:1942-51.

Hegewald MJ, Crapo RO. 2007. Socioeconomic status and lung function. Chest, 132:1608-14.

Herland K, Akselen J-P, Skjonsberg OH, et al. 2005. How representative are clinical study patients with asthma or COPD for a larger "real life" population of patients with obstructive lung disease? Respir Med, 99:11-9.

Jackevicius C, Joyce DP, Kesten S, et al. 1997. Prehospitalization inhaled corticosteroid use in patients with COPD and asthma. Chest, 111:296-302.

Jemal A, Ward E, Hao Y, et al. 2005. Trends in the leading causes of death in the United States, 1970-2002. JAMA, 294:1255-9.

Kim DS, Kim YS, Jung K-S, et al. 2005. Prevalence of chronic obstructive pulmonary disease in Korea. A population-based spirometry survey. Am J Respir Crit Care Med, 172:842-7.

Menezes AM, Perez-Padilla R, Jardim JR, et al. 2005.PLATINO Team. Chronic obstructive pulmonary disease in five Latin American cities (the PLATINO study): a prevalence study. Lancet, 366:1875-81.

Miravitlles M, Anzueto A, Legnani D, et al. 2007. Patient's perception of exacerbations of COPD - the PERCEIVE study. Respir Med, 101:453-60.

Miravitlles M, de la Roza C, Morera J, et al. 2006. Chronic respiratory symptoms, spirometry and knowledge of COPD among general population. Respir Med, 100:1973-80.
Miravitlles M, de la Roza C, Naberan K, et al. 2007. Use of spirometry and patterns of prescribing in COPD in primary care. Respir Med, 101:1753-60.

Miravitlles M, Ferrer M, Pont A, et al. 2005. Characteristics of a population of COPD patients identified from a population-based study. Focus on previous diagnosis and never smokers. Respir Med, 99:985-95.

Miravitlles M, Llor C, Naberan K, et al. 2002. Use of the internet in a multicenter study on chronic obstructive pulmonary disease in primary care. Pilot phase of the EFEMAP study. Arch Bronconeumol, $38: 427-430$

Miravitlles M, Mayordomo C, Artés M, et al. on Behalf of the EOLO Group. 1999. Treatment of chronic obstructive pulmonary disease and its exacerbations in General Practice. Respir Med, 93:173-9.

Montnémery OP, Bengtsson P, Elliot A, et al. 2001. Prevalence of obstructive lung diseases and respiratory symptoms in relation to living environment and socio-economic group. Respir Med, 95:744-52.

Pauwels RA, Buist AS, Calverley PMA, et al. 2001. Global strategy for the diagnosis, management, and prevention of chronic obstructive pulmonary disease. NHLBI/WHO global initiative for chronic obstructive lung disease (GOLD) workshop summary. Am J Respir Crit Care Med, 163:1256-76.

Ramirez-Venegas A, Sansores RH, Pérez-Padilla R, et al. 2006. Survival of patients with chronic obstructive pulmonary disease due to biomass smoke and tobacco. Am J Respir Crit Care Med, 173:393-7.

Rennard S, Decramer M, Calverley PM, et al. 2002. Impact of COPD in North America and Europe in 2000: subjects' perspective of confronting COPD International Survey. Eur Respir J, 20:799-805.

Roche N, Lepage T, Bourcereau J, et al. 2001. Guidelines versus clinical practice in the treatment of chronic obstructive pulmonary disease. Eur Respir J, 18:903-8.

Siva R, Green RH, Brightling CE, et al. 2007. Eosinophilic airway inflammation and exacerbations of COPD: a randomised controlled trial. Eur Respir J, 29:906-13.

Sobradillo V, Miravitlles M, Gabriel R, et al. 2000. Geographical variations in prevalence and underdiagnosis of COPD. Results of the IBERPOC multicentre epidemiological study. Chest, 118:981-9.

Van Andel AE, Reisner C, Menjoge SS, et al. 1999. Analysis of inhaled corticosteroid and oral theophylline use among patients with stable COPD from 1987 to 1995. Chest, 115:703-7.

Viejo-Bañuelos JL, Pueyo-Bastida A, Fueyo-Rodriguez A. 2006. Characteristics of outpatients with COPD in daily practice: The E4 Spanish project. Respir Med, 100:2137-43.

Wang Y-C, Lin J-M, Li C-Y, et al. 2007. Prevalence and risks of chronic airway obstruction. A population cohort study in Taiwan. Chest, 131:705-10

Zhong N, Wang C, Yao W, et al. 2007. Prevalence of chronic obstructive pulmonary disease in China. A large, population-based survey. Am J Respir Crit Care Dis, 176:753-60. 


\section{Appendix I}

\section{Organization of the EPOCA study}

Scientific Committee

Marc Miravitlles (Barcelona, Spain), Antonio Anzueto (San

Antonio, TX, United States), Gur Levy (Caracas, Venezuela), Cristina Murio (Barcelona, Spain), Joan B Soriano (Buñola, Spain), Hana Muellerova (Greenford, United Kingdom).

The following investigators participated in the study:

Argentina: Pablo Luis Acrogliano; Miguel Bergna; Carmela Echagúe; Mariano Fernández Acquier; Juan C. Figueroa Casas; Gabriel García; Eduardo Giugno; Georgina Gramblicka; Julio Alberto Herscovich; Néstor Sergioka Hanovsky; José María Leston; Eduardo Héctor Marzorati; María Cristina Ortiz; Salvador Antonio Pace; Fernando Saldarini; José Luis Sarquis; Mirta Beatriz Scarinci; Marcela Soria; Carlos Fabián Victorio; Nora Miriam Zanollo.

Brazil: José R. Jardim; Fátima Saia Gonzaga; Carlos Eduardo Do Valle Ribeiro. Chile: Paulina Barría Pérez; Patricio Jiménez; Carmen Lisboa; Cuba: Yadira Dobarganes Sansón; Alfredo Jané Lara. Ecuador: Betty María Aguilar De Bajaña; Oswaldo Bastidas Jervez; Carlos Andrés Beltrán
Bastidas; Byron Canelos Estrella; Iván Cherrez Ojeda; José Matías Desiderio Rodrigo; Melida Herlinda Jacome Escobar; Carlos Patricio Rosero Herrera. Spain: Cristian De La Roza Fernández; Mikel Egurrola Izquierdo; Cristina Estirado Vera; Xavier Flor Escriche; Beatriz Lara; Montserrat Mas Pujol; José Antonio Quintano Jimenez; Joan Sala Barbany; Alejandro Sanchez Acosta; Juan José Soler Cataluña; Xavier Soler Tomas; Ángel Tirado Conde; Gema Tirado Conde; Sara Vilà Valls; Greece: Epaminondas Kosmas. Honduras: Carlos Aguilar. Hong-Kong: Fanny WS Ko. Italy: Francesco Blasi; Luca Richeldi. Mexico: Javier Díaz-Castañon; Carlos Adrian Jiménez González; Alejandra Ramírez Venegas; Raúl Sansores. Peru: Alberto Matsuno Fuchigami. Poland: Nowinski Adam; Justyna Czerniawska; Anna Czyzak; Jacek Kolakowski; Damian Korzybski. Russia: Ekaterina Bukreeva; Sofya Nesterovich; María Sanzharovskaja. South Africa: Gillian Ainslie. Uruguay: María Turquesa Anido Donceli; María Victoria López Varela; Monica Mamchur Galvez; Sandra Peña Miraldo. Venezuela: Federico Arteta; Gur Levy.

Statistical analysis: Montse Pérez, Barcelona, Spain. 
